\title{
Fertility preservation in women affected by gynaecological cancer: the importance of an integrated gynaecological and psychological approach
}

\author{
Valentina Lucia La Rosa ${ }^{1}$, Simone Garzon², Giuseppe Gullo ${ }^{3}$, Michele Fichera ${ }^{4}$, Giovanni Sisti ${ }^{5}$, Pasquale Gallo ${ }^{6}$, Gaetano Riemma7 and \\ Antonio Schiattarella ${ }^{7}$
}

${ }^{1}$ Unit of Psychodiagnostics and Clinical Psychology, University of Catania, Catania, Italy

${ }^{2}$ Department of Obstetrics and Gynaecology, "Filippo Del Ponte" Hospital, University of Insubria, Varese, Italy

${ }^{3}$ Department of Obstetrics and Gynaecology, AOOR Villa Sofia Cervello, IVF Public Center, Palermo, Italy

${ }^{4}$ Department of General Surgery and Medical Surgical Specialties, University of Catania, Catania, Italy

${ }^{5}$ Lincoln Medical and Mental Health Center, 234 East 149 Street, 5th Floor, Bronx, NY 10451, USA

${ }^{4}$ Obstetrics and Gynaecology Unit, "Santa Maria delle Grazie" Hospital, Pozzuoli, Naples, Italy

${ }^{7}$ Department of Woman, Child and General and Specialised Surgery, University of Campania "Luigi Vanvitelli", Naples, Italy

\section{Abstract}

Gynaecological cancer treatment significantly affects the fertility of women in reproductive age. Surgery, chemotherapy and radiotherapy are the mainstays of ovarian, cervical and endometrial cancers and anatomically or functionally impact the uterus and ovaries. Moreover, the sexual function and psychological wellbeing of patients are highly weakened after a cancer diagnosis: depression, anxiety and impairment of quality of life represent a relevant concern for patient care. The potential loss of fertility could be more distressing than cancer itself. For this reason, it is of paramount importance to try to preserve fertility in women affected by gynaecological cancers. Recently, tailored fertility preservation therapies have been developed to meet the childbearing demand from more than half of women between 18 and 40 years with a diagnosis of cancer. Currently, fertility preservation techniques play a significant role in improving the quality of life of women with gynaecological cancer. In this scenario, we propose a narrative overview of the recent literature about the importance of a multidisciplinary approach in the management of fertility preservation in the case of gynaecological cancers.

Keywords: fertility preservation, reproduction, quality of life, gynecological cancer, endometrial cancer, cervical cancer, ovarian cancer, fertility-sparing surgery

\section{Introduction}

The annual global cancer burden is estimated to reach about 18 million cases and more than 9 million deaths [1, 2]. Gynaecological cancers have a prevalence of $15 \%-20 \%$ of the total neoplasms involving women. The most common is uterine cancer (53\%) [3-5], followed by ovarian (25\%) [6, 7], cervical (14\%) [8-10], vaginal and vulvar cancers [11-13], with more rare neoplastic forms, such as trophoblastic tumours [14]. About 20\% of gynaecological cancer affects women under 40 years of age, who often have not completed

Correspondence to: Valentina Lucia La Rosa Email:valarosa@unict.it

ecancer 2020, 14:1035

https://doi.org/10.3332/ecancer.2020.1035

Published: 06/05/2020

Received: 31/12/2019

Publication costs for this article were supported by ecancer (UK Charity number 1176307).

Copyright: (c) the authors; licensee ecancermedicalscience. This is an Open Access article distributed under the terms of the Creative Commons Attribution License (http:// creativecommons.org/licenses/by/3.0), which permits unrestricted use, distribution, and reproduction in any medium, provided the original work is properly cited. 
parity or are before their first pregnancy [15-20]. In these patients, fertility preservation represents a unique point of paramount importance. Surgical therapy is demolitive for the reproductive organs in the majority of cases, and chemotherapy and radiotherapy affect the function of the uterus and ovaries if preserved. For these reasons, recent guidelines recommend that although the initial focus is on the cancer diagnosis, healthcare providers should discuss with their patients the impact of cancer treatments on fertility from the earliest stages of therapy, in order to guide women in choosing between different fertility preservation options [21-23].

In addition to the loss of function, the psychological consequences can sometimes be more significant. Sexuality and couple relationships can be severely affected in these patients, especially because gynaecological cancer has a strong impact on the female identity and threatens their feelings about their sexuality $[24,25]$. Recent studies support the idea that infertility has implications that go beyond the immediate reproductive needs of patients [24, 25]. Many of these women greatly benefit from working on crucial psychosexual issues within a psychotherapeutic setting [26]. According to these considerations, it is evident that fertility preservation has fundamental importance for these women. Indeed, the literature about this topic confirms that patients think about fertility counselling as an essential issue in their care pathway. Moreover, adequate fertility preservation counselling allows the reduction of feelings of anxiety and worry related to fertility and improvement of health-related quality of life significantly [27, 28].

In this scenario, the purpose of this mini-review is to provide an overview of the impact of gynaecological cancer on women in reproductive age, deepening the importance of a multidisciplinary approach to fertility preservation.

\section{The impact of cancer and fertility preservation on quality of life}

The prevalence of cancer diagnosis at childbearing age is increasing, while mortality continues to reduce [29]. This aspect presents various causes, such as primary prevention, widespread screening and improvement of diagnostic tools and treatment efficacy [1, 30]. New shreds of evidence report that about $75 \%$ of these reproductive-aged women diagnosed with cancer refer childbearing wishes [27, 31]; therefore, new priorities need to be set.

The diagnosis of gynaecological cancer represents a hard-emotional impact on women. Young women with gynaecological cancer experience the loss of menstruation and fertility with particular anxiety and stress. In particular, it has been underlined that psychological distress related to infertility is more pronounced in women who have not yet created their families and would still like to do so [24, 25, 32]. Furthermore, the literature on the topic reports a significant presence of anxiety, depression, low self-esteem, anger, irrational beliefs about cancer, suicidal thoughts and sleep disorders in women with gynaecological cancer [27, 31-33].

Sexual dysfunctions are one of the most frequent side effects of cancer therapies. Their prevalence in women surviving gynaecological cancer is estimated at $40 \%$ to $100 \%$ compared with about $19 \%$ to $50 \%$ of the healthy female population [34, 35]. Indeed, cancer can cause profound changes in the body image, especially in the cases of premature infertility or surgical disfigurement. In turn, a negative body image is associated with decreased sexual functioning and increased discomfort during intercourse [36]. Furthermore, all major cancer treatments (surgery, radiotherapy, chemotherapy and hormonal therapy) are associated with a significant impairment of sexual function [37]. According to the American Cancer Society, the most frequent female sexual problems caused by cancer treatments include vaginal dryness, low sexual desire, dyspareunia and difficulty in reaching orgasm [36, 38].

Several studies have investigated the impact of reproductive cancers on sexual satisfaction and needs of women of reproductive age. Mütsch et al [39] investigated sexual function and the needs related to the sexual sphere of adolescents and young women affected by both reproductive and other types of cancer. According to their results, sexuality is significantly worse in women with tumours affecting the reproductive sphere. More specifically, the Authors reported a significant deterioration of sexual satisfaction, changes in sexuality and increased sexual supportive care needs [39]. Similar data were highlighted in the study by Geue et al [40], which investigated couple relationships and sexuality in adolescents and young adults with cancer. According to the Authors, these patients reported high satisfaction with their relationships but, at the same time, experienced sexual problems and need support in dealing with sexual problems [40].

The awareness of having cancer implies a real regret for the perception of oneself, one's health, one's identity as a woman and mother, as well as one's wellbeing in general [41]. The life of a woman with gynaecological cancer is, therefore, severely impaired, as well as the idea of death 
changes the prospects and life priorities [42, 43]. Also, the perception of time changes: the future seems to be threatening and the present is distressing [33, 42]. The self-image is essentially modified, and there is a decrease in psychological, sexual and social well-being. Personal identity is impaired, and the ability to cope with stress and planning can be compromised $[13,44,45]$. In this scenario, pregnancy and motherhood also take on an important symbolic value which should not be overlooked. Indeed, for a woman who survives cancer, motherhood is of fundamental importance becoming a mother is the symbol of hope in the future and of the life that wins over death [28, 46]. Consequently, the opportunity of achieving a pregnancy and having a child after a malignancy significantly improves the therapeutic process: in fact, the woman is more motivated to accurately follow the therapy and faces it with greater tranquility [27, 47-49]. For this reason, the possibility of procreating after cancer might be interpreted as an essential element of protection [48, 50, 51].

For all these reasons, fertility preservation techniques are important to improve quality of life of women with gynaecological cancer [28]. In this regard, it is mandatory to strictly follow the progression of cancer; however, it is equally crucial to improve as much as possible the patient's psychosexual wellbeing, her quality of life and psychosocial functioning, due to the fact that these aspects affect both the compliance as well as the effectiveness of the therapy itself [17, 25, 52].

Nevertheless, proper information and expert counselling should focus on propose a unique plan for the single patient, taking into account her life perspective that can be acquired on active comprehension and listening of her needs, desires, fears and doubts. Furthermore, it is also important to provide an adequate sexual counselling, especially about decreased libido, inability to achieve orgasm, dyspareunia, vaginal dryness or loss of sexual pleasure [36]. However, it has been shown that clinicians rarely address psychological and sexual issues with gynaecological cancer patients. This difficulty can be explained by the lack of adequate knowledge and communication skills on the topic [53]. At the same time, the woman may avoid confronting these topics with the clinician because of a sense of embarrassment. As a consequence, the woman is most at risk of developing anxiety and depression [36]. For these reasons, it is very important that the health care professional has basic knowledge on the impact of cancer and its treatments on the patient's psychological and sexual sphere in order to improve communication as well as the adherence to the proposed treatments [28]. For this purpose, the involvement of a psychologist in the multidisciplinary team deeply reduces the level of stress, anxiety, and depression. Moreover, it allows a better adherence to therapy, reducing the negative impact on women's quality of life $[12,59,60]$.

\section{The importance of counselling for fertility preservation}

It has been widely demonstrated that the different options for preserving fertility in women with gynaecological cancer are effective in improving the quality of life of these patients [47, 54]. Different studies confirmed the positive association between the proposal on fertility preservation treatments and the quality of life improvement of cancer survivors [51, 52]. Based on this purpose, a fertility preservation counselling can be offered at all women, including those in pre- and post-pubertal age [55, 56]. In recent years, several guidelines and clinical recommendations concerning fertility preservation techniques have been developed. They strongly recommend that patients should be informed on available fertility preservation options before starting anticancer treatments [22, 57]. However, limited information about these treatments still exists, and women are quite often uninformed about choices and possibilities [47]. In addition, the physician should acknowledge that it is mandatory to give advices that should be related to reproductive prognosis and the risk of treatment for infertility $[22,47,58]$. Other important aspects should be considered in order to provide the best fertility preservation advices. The patient's decision on fertility conservation are also impacted by financial resources, prejudices, lack of adequate support, anxiety and doubts about treatments [59]. For this reason, only the knowledge of an expert physician could offer adequate information and gives the possibility of listening to the women's suffering and doubts $[58,60,61]$.

Concerning this point, some studies have investigated oncologists' practice and attitude about fertility preservation. Some of them underlined that almost one-third of oncologists are not able to explain fertility issues [62]. Although so, most physicians offer high visibility to the problem and provide information about fertility preservation options [61, 63]. Physicians' difficulty in talking about preserving fertility is generally due to their insufficient knowledge regarding these techniques as well as to the lack of specific communication strategies [47, 64]. In this regard, the communication between patient and physician about fertility preservation may be influenced by several factors such as physician knowledge of fertility preservation techniques and their efficacy, patient's anxiety and stress and economic problems [65]. Other 
factors may also affect the effectiveness of fertility preservation counselling. For example, cognitive aspects, such as biases and heuristics, may make decision-making about fertility preservation more difficult and less aware [59]. In these cases, decision support interventions or decision aids can be useful to reduce possible biases in the decision-making process [59]. More specifically, decision aids provide information about cancer and female fertility, discussing the different available fertility options and the advantages and disadvantages of each one [68]. This type of approach is very useful in increasing knowledge and reducing decisional conflict without increasing anxiety. The P5 approach can help to improve decision-making about fertility preservation, transforming women into active decision-makers in the treatment process [67].

For all these reasons, it is important that reproductive counselling is carried out by a multidisciplinary team that also includes a psychologist $[27,47]$. Indeed, the new concept of oncofertility represents a new crucial challenge in the treatment and assistance of cancer patients. In this regard, the Oncofertility Consortium can be considered an example of an adequate multidisciplinary approach for fertility preservation that includes oncology, reproductive medicine and public health $[68,69]$.

\section{Conclusion}

Fertility preservation techniques can be effective in the improvement of the quality of life of women with gynaecological cancers. The clinical experience and the international literature about the topic deepen the importance of the role of quality of life on psychological outcomes

[48]. The objective of a better life for the cancer survivor and the hope of becoming a mother represent a fundamental aspect of improving self-esteem. Future studies are necessary to develop effective therapeutic counselling approaches to be combined with oncological therapies with the aim of reducing the psychological impact of the cancer experience and improving the quality of life for women.

\section{Conflicts of interest}

The authors declare that they have no conflicts of interest.

\section{Funding statement}

No funding was obtained for this study.

\section{References}

1. Ferlay J, Colombet M, and Soerjomataram I, et al (2019) Estimating the global cancer incidence and mortality in 2018: GLOBOCAN sources and methods Int J Cancer 144(8) 1941-1953 https://doi.org/10.1002/ijc.31937

2. Vitale SG, Capriglione S, and Zito G, et al (2019) Management of endometrial, ovarian and cervical cancer in the elderly: current approach to a challenging condition Arch Gynecol Obstet 299(2) 299-315 https://doi.org/10.1007/s00404-018-5006-z

3. Vitale SG, Rossetti D, and Tropea A, et al (2017) Fertility sparing surgery for stage IA type I and G2 endometrial cancer in reproductive-aged patients: evidence-based approach and future perspectives Updates Surg 69(1) 29-34 https://doi.org/10.1007/s13304-0170419-y PMID: 28188573

4. Carneiro MM, Lamaita RM, and Ferreira MCF, et al (2016) Fertility-preservation in endometrial cancer: is it safe? Review of the literature JBRA Assist Reprod 20(4) 232-239 https://doi.org/10.5935/1518-0557.20160045

5. Cignini P, Vitale SG, and Laganà AS, et al (2017) Preoperative work-up for definition of lymph node risk involvement in early stage endometrial cancer: 5-year follow-up Updates Surg 69(1) 75-82 https://doi.org/10.1007/s13304-017-0418-z PMID: 28108938 
6. Bellia A, Vitale SG, and Laganà AS, et al Feasibility and surgical outcomes of conventional and robot-assisted laparoscopy for earlystage ovarian cancer: a retrospective, multicenter analysis Arch Gynecol Obstet 294(3) 615-622 PMID: 27040423

7. Bentivegna E, Gouy S, and Maulard A, et al (2016) Fertility-sparing surgery in epithelial ovarian cancer: a systematic review of oncological issues Ann Oncol Off J Eur Soc Med Oncol 27(11) 1994-2004 https://doi.org/10.1093/annonc/mdw311

8. Vitale SG, Valenti G, and Rapisarda AMC, et al (2016) P16INK4a as a progression/regression tumour marker in LSIL cervix lesions: our clinical experience Eur J Gynaecol Oncol 37(5) 685-688 PMID: 29787011

9. Valenti G, Vitale SG, and Tropea A, et al (2017) Tumor markers of uterine cervical cancer: a new scenario to guide surgical practice? Updates Surg 69(4) 441-449 https://doi.org/10.1007/s13304-017-0491-3 PMID: 28918603

10. Schettino MT, De Franciscis P, and Schiattarella A, et al (2019) Prevalence of HPV Genotypes in South Europe: Comparisons between an Italian and a Turkish Unvaccinated Population J Environ Public Health 2019 1-7 https://doi.org/10.1155/2019/8769735

11. Siegel RL, Miller KD, and Jemal A (2018) Cancer statistics, 2018 CA Cancer J Clin 68(1) 7-30 https://doi.org/10.3322/caac.21442 PMID: 29313949

12. Davidovic-Grigoraki M, Thomakos N, and Haidopoulos D, et al (2017) Do critical care units play a role in the management of gynaecological oncology patients? The contribution of gynaecologic oncologist in running critical care units Eur J Cancer Care (Engl) 26(2) https:// doi.org/10.1111/ecc.12438

13. Jeppesen MM, Mogensen O, and Dehn P, et al (2015) Needs and priorities of women with endometrial and cervical cancer J Psychosom Obstet Gynaecol 36(3) 122-132 https://doi.org/10.3109/0167482X.2015.1059417 PMID: 26123123

14. Chiofalo B, Palmara V, and Laganà AS, et al (2017) Fertility sparing strategies in patients affected by placental site trophoblastic tumor Curr Treat Options Oncol 18(10) 58 https://doi.org/10.1007/s11864-017-0502-0 PMID: 28840513

15. Cantrell LA and Backes F (2017) Highlights from the Society of Gynecologic Oncology 2017 Annual Meeting on Women's Cancer Gynecol Oncol 145(3) 483-485 https://doi.org/10.1016/j.ygyno.2017.04.002 PMID: 28456377

16. Temkin SM, Rimel BJ, and Bruegl AS, et al (2018) A contemporary framework of health equity applied to gynecologic cancer care: a Society of Gynecologic Oncology evidenced-based review Gynecol Oncol 149(1) 70-77 https://doi.org/10.1016/j.ygyno.2017.11.013 PMID: 29605053

17. Salani R, Billingsley CC, and Crafton SM (2014) Cancer and pregnancy: an overview for obstetricians and gynecologists Am J Obstet Gynecol 211(1) 7-14 https://doi.org/10.1016/j.ajog.2013.12.002

18. McKenzie ND, Kennard JA, and Ahmad S (2018) Fertility preserving options for gynecologic malignancies: a review of current understanding and future directions Crit Rev Oncol Hematol 132 116-124 https://doi.org/10.1016/j.critrevonc.2018.09.020 PMID: 30447916

19. Vitale SG (2019) The Biopsy Snake Grasper Sec. VITALE: A New Tool for Office Hysteroscopy J Minim Invasive Gynecol pii: S15534650(19)31362-7 https://doi.org/10.1016/j.jmig.2019.12.014 PMID: 31884079

20. Mele D, De Franciscis P, and Cosenza C, et al (2019) Surgical management of endometrioma for ovarian safety Ital J Gynaecol Obstet 31(3) 49-55

21. Oktay K, Harvey $\mathrm{BE}$, and Partridge $\mathrm{AH}$, et al (2018) Fertility preservation in patients with cancer: ASCO clinical practice guideline update J Clin Oncol 36(19) 1994-2001 https://doi.org/10.1200/JCO.2018.78.1914 PMID: 29620997

22. Lambertini M, Del Mastro L, and Pescio MC, et al (2016) Cancer and fertility preservation: international recommendations from an expert meeting BMC Med 141 https://doi.org/10.1186/s12916-015-0545-7 PMID: 26728489 PMCID: 4700580

23. Smith BM, Duncan FE, and Ataman L, et al (2018) The National Physicians Cooperative: transforming fertility management in the cancer setting and beyond Future Oncol 14(29) 3059-3072 https://doi.org/10.2217/fon-2018-0278 PMID: 30474429 PMCID: 6331694 
24. Huffman LB, Hartenbach EM, and Carter J, et al (2016) Maintaining sexual health throughout gynecologic cancer survivorship: a comprehensive review and clinical guide Gynecol Oncol 140 359-368 https://doi.org/10.1016/j.ygyno.2015.11.010 PMCID: 4835814

25. Carter J, Stabile C, and Gunn A, et al (2013) The physical consequences of gynecologic cancer surgery and their impact on sexual, emotional, and quality of life issues J Sex Med 10(suppl) 21-34 https://doi.org/10.1111/jsm.12002 PMID: 23387909

26. Sacerdoti RC, Lagana' L, and Koopman C (2010) Altered sexuality and body image after gynecological cancer treatment: how can psychologists help? Prof Psychol Res Pr 41(6) 533-540 https://doi.org/10.1037/a0021428

27. Deshpande NA, Braun IM, and Meyer FL (2015) Impact of fertility preservation counseling and treatment on psychological outcomes among women with cancer: a systematic review Cancer 121(22) 3938-3947 https://doi.org/10.1002/cncr.29637 PMID: 26264701

28. Laganà AS, La Rosa VL, and Rapisarda AMC, et al (2017) Psychological impact of fertility preservation techniques in women with gynaecological cancer Ecancermedicalscience 11 ed62 https://doi.org/10.3332/ecancer.2017.ed62 PMID: 28275393 PMCID: 5336386

29. Miller KD, Nogueira L, and Mariotto AB, et al (2019) Cancer treatment and survivorship statistics, 2019 CA Cancer J Clin 69(5) 363-385 https://doi.org/10.3322/caac.21565 PMID: 31184787

30. Bray F, Ferlay J, and Soerjomataram I, et al (2018) Global cancer statistics 2018: GLOBOCAN estimates of incidence and mortality worldwide for 36 cancers in 185 countries CA Cancer J Clin 2018 68(6) 394-424 https://doi.org/10.3322/caac.21492 PMID: 30207593

31. La Rosa VL, Shah M, and Kahramanoglu I, et al (2019) Quality of life and fertility preservation counseling for women with gynecological cancer: an integrated psychological and clinical perspective J Psychosom Obstet Gynaecol 1-7 https://doi.org/10.1080/01674 82X.2019.1648424

32. Iżycki D, Woźniak K, and lżycka N (2016) Consequences of gynecological cancer in patients and their partners from the sexual and psychological perspective Prz menopauzalny = Menopause Rev 15(2) 112-116 https://doi.org/10.5114/pm.2016.61194

33. Chan JL and Wang ET (2017) Oncofertility for women with gynecologic malignancies Gynecol Oncol 144(3) 631-636 https://doi. org/10.1016/j.ygyno.2016.12.013

34. Shankar A, Prasad N, and Roy S, et al (2017) Sexual dysfunction in females after cancer treatment: an unresolved issue Asian Pac J Cancer Prev 18(5) 1177-1182 PMID: 28610399 PMCID: 5555520

35. La Rosa VL, De Franciscis P, and Barra F, et al (2020) Sexuality in women with endometriosis: a critical narrative review Minerva Med 111(1) 79-89 https://doi.org/10.23736/S0026-4806.19.06299-2 PMID: 31726815

36. Audette $C$ and Waterman J (2010) The sexual health of women after gynecologic malignancy J Midwifery Womens Health 55(4) 357-362 https://doi.org/10.1016/j.jmwh.2009.10.016 PMID: 20630362

37. Bober SL, Kingsberg SA, and Faubion SS (2019) Sexual function after cancer: paying the price of survivorship Climacteric 22(6) 558-564 https://doi.org/10.1080/13697137.2019.1606796 PMID: 31090466

38. American Cancer Society. Sexual impact following breast cancer treatment [Internet]

39. Mütsch J, Friedrich M, and Leuteritz K, et al (2019) Sexuality and cancer in adolescents and young adults - a comparison between reproductive cancer patients and patients with non-reproductive cancer BMC Cancer 19(1) 828 https://doi.org/10.1186/s12885-0196009-2 PMID: 31438895 PMCID: 6704507

40. Geue K, Schmidt R, and Sender A, et al (2015) Sexuality and romantic relationships in young adult cancer survivors: satisfaction and supportive care needs Psychooncology 24(11) 1368-1376 https://doi.org/10.1002/pon.3805 PMID: 25826748

41. Grassi L, Gritti P, and Rigatelli M, et al (2000) Psychosocial problems secondary to cancer Eur J Cancer 36(5) 579-585 https://doi. org/10.1016/S0959-8049(99)00285-3 PMID: 10738121 
42. Naughton MJ and Weaver KE (2014) Physical and mental health among cancer survivors N C Med J 75(4) 283-286 PMID: 25046097 PMCID: 4503227

43. Edwards B and Clarke V (2004) The psychological impact of a cancer diagnosis on families: the influence of family functioning and patients' illness characteristics on depression and anxiety Psychooncology 13(8) 562-576 https://doi.org/10.1002/pon.773 PMID: 15295777

44. Schaeffeler N, Pfeiffer K, and Ringwald J, et al (2015) Assessing the need for psychooncological support: screening instruments in combination with patients' subjective evaluation may define psychooncological pathways Psychooncology 24(12) 1784-1791 https://doi. org/10.1002/pon.3855 PMID: 26042392

45. Faller $\mathrm{H}$, Weis $\mathrm{J}$, and Koch $\mathrm{U}$, et al (2016) Perceived need for psychosocial support depending on emotional distress and mental comorbidity in men and women with cancer J Psychosom Res 81 24-30 https://doi.org/10.1016/j.jpsychores.2015.12.004 PMID: 26800635

46. Tschudin S and Bitzer J (2009) Psychological aspects of fertility preservation in men and women affected by cancer and other lifethreatening diseases Hum Reprod Update 15(5) 587-597 https://doi.org/10.1093/humupd/dmp015 PMID: 19433413

47. Angarita AM, Johnson CA, and Fader AN, et al (2016) Fertility preservation: a key survivorship issue for young women with cancer Front Oncol 6102 https://doi.org/10.3389/fonc.2016.00102 PMID: 27200291 PMCID: 4843761

48. Bodurka-Bevers D, Basen-Engquist K, and Carmack CL, et al (2000) Depression, anxiety, and quality of life in patients with epithelial ovarian cancer Gynecol Oncol 78(3) 302-308 https://doi.org/10.1006/gyno.2000.5908 PMID: 10985884

49. Letourneau JM, Ebbel EE, and Katz PP, et al (2012) Pretreatment fertility counseling and fertility preservation improve quality of life in reproductive age women with cancer Cancer 118(6) 1710-1717 https://doi.org/10.1002/cncr.26459

50. Schover LR (1999) Psychosocial aspects of infertility and decisions about reproduction in young cancer survivors: a review Med Pediatr Oncol 33(1) 53-59 https://doi.org/10.1002/(SICI)1096-911X(199907)33:1<53::AID-MPO10>3.0.CO;2-K PMID: 10401498

51. Chin HB, Howards PP, and Kramer MR, et al (2016) Which female cancer patients fail to receive fertility counseling before treatment in the state of Georgia? Fertil Steril 106(7) 1763-1771.e1 https://doi.org/10.1016/j.fertnstert.2016.08.034 PMID: 27678034 PMCID: 5136299

52. Hart R (2008) Preservation of fertility in adults and children diagnosed with cancer BMJ 337 a2045 https://doi.org/10.1136/bmj.a2045 PMID: 18955375

53. Stead ML, Brown JM, and Fallowfield L, et al (2003) Lack of communication between healthcare professionals and women with ovarian cancer about sexual issues Br J Cancer 88(5) 666-671 https://doi.org/10.1038/sj.bjc.6600799 PMID: 12618871 PMCID: 2376341

54. Maltaris T, Boehm D, and Dittrich R, et al (2006) Reproduction beyond cancer: a message of hope for young women Gynecol Oncol 103(3) 1109-1121 https://doi.org/10.1016/j.ygyno.2006.08.003 PMID: 16996582

55. Knight S, Lorenzo A, and Maloney AM, et al (2015) An approach to fertility preservation in prepubertal and postpubertal females: a critical review of current literature Pediatr Blood Cancer 62(6) 935-939 https://doi.org/10.1002/pbc.25440 PMID: 25739552

56. Algarroba GN, Sanfilippo JS, and Valli-Pulaski H (2018) Female fertility preservation in the pediatric and adolescent cancer patient population Best Pract Res Clin Obstet Gynaecol 48 147-157 https://doi.org/10.1016/j.bpobgyn.2017.10.009

57. Peccatori FA, Azim HA, and Orecchia R, et al (2013) Cancer, pregnancy and fertility: ESMO Clinical Practice Guidelines for diagnosis, treatment and follow-up Ann Oncol Off J Eur Soc Med Oncol 24(Suppl 6) vi160-170 https://doi.org/10.1093/annonc/mdt199

58. Lawson AK, Klock SC, and Pavone ME, et al (2015) Psychological counseling of female fertility preservation patients J Psychosoc Oncol 33(4) 333-353 https://doi.org/10.1080/07347332.2015.1045677 PMID: 25996581 PMCID: 4557874

59. Gorini A and Pravettoni G (2011) An overview on cognitive aspects implicated in medical decisions Eur J Intern Med 22(6) 547-553 https://doi.org/10.1016/j.ejim.2011.06.008 PMID: 22075278 
60. Baysal Ö, Bastings L, and Beerendonk CCM, et al (2015) Decision-making in female fertility preservation is balancing the expected burden of fertility preservation treatment and the wish to conceive Hum Reprod 30(7) 1625-1634 https://doi.org/10.1093/humrep/ dev116 PMID: 26034191

61. Bastings L, Baysal O, and Beerendonk CCM, et al (2014) Deciding about fertility preservation after specialist counselling Hum Reprod 29(8) 1721-1729 https://doi.org/10.1093/humrep/deu136 PMID: 24916435

62. Louwé LA, Stiggelbout AM, and Overbeek A, et al (2018) Factors associated with frequency of discussion of or referral for counselling about fertility issues in female cancer patients Eur J Cancer Care (Engl) 27(1) https://doi.org/10.1111/ecc.12602

63. Sallem A, Shore J, and Ray-Coquard I, et al (2018) Fertility preservation in women with cancer: a national study about French oncologists awareness, experience, and feelings J Assist Reprod Genet 35(10) 1843-1850 https://doi.org/10.1007/s10815-018-1251-0 PMID: 29974370 PMCID: 6150902

64. Quinn GP, Vadaparampil ST, and Gwede CK, et al (2007) Discussion of fertility preservation with newly diagnosed patients: oncologists' views J Cancer Surviv 1(2) 146-155 https://doi.org/10.1007/s11764-007-0019-9

65. Quinn GP, Vadaparampil ST, and Bell-Ellison BA, et al (2008) Patient-physician communication barriers regarding fertility preservation among newly diagnosed cancer patients Soc Sci Med 66(3) 784-789 https://doi.org/10.1016/j.socscimed.2007.09.013

66. Peate M, Meiser B, and Cheah BC, et al (2012) Making hard choices easier: a prospective, multicentre study to assess the efficacy of a fertility-related decision aid in young women with early-stage breast cancer Br J Cancer 106(6) 1053-1061 https://doi.org/10.1038/ bjc.2012.61 PMID: 22415294 PMCID: 3304428

67. Pravettoni G and Gorini A (2011) A P5 cancer medicine approach: why personalized medicine cannot ignore psychology J Eval Clin Pract 17(4) 594-596 https://doi.org/10.1111/j.1365-2753.2011.01709.x PMID: 21679280

68. Woodruff TK (2010) The oncofertility consortium-addressing fertility in young people with cancer Nat Rev Clin Oncol 7(8) 466-475 https://doi.org/10.1038/nrclinonc.2010.81 PMID: 20498666 PMCID: 3124936

69. Woodruff TK (2015) Oncofertility: a grand collaboration between reproductive medicine and oncology Reproduction 150(3) S1-S10 https://doi.org/10.1530/REP-15-0163 PMID: 26130814 PMCID: 4710491 